\title{
Lipofactory: Yarrowia lipolytica as a cell factory to produce microbial oils from hydrophobic
} substrates

Marlene Lopes*, Sílvia M. Miranda, Ana S. Pereira, Isabel Belo

Centre of Biological Engineering, University of Minho, Braga, Portugal

E-mail address: marlenelopes@deb.uminho.pt (M. Lopes).

Yarrowia lipolytica, an oleaginous yeast, is an adequate cell factory platform to convert low-value hydrophobic substrates into microbial oils and other important metabolites.

The ability of Y. lipolytica W29 to produce microbial oils and other compounds (lipase and citric acid) from waste cooking oils (WCO) and animal fat (lard) was evaluated and the effect of several factors were assessed by an experimental design. OTR and $\mathrm{pH}$ was by far the most influential parameters for microbial oils production by Y. lipolytica W29 from lard and from WCO, respectively. Regardless of hydrophobic substrate used, the yeast oil content obtained (58\% from lard and 53\% from WCO) was one of the higher ever reported for a non-genetically modified $Y$. lipolytica strain. The unsaturated-to-saturated fatty acids ratio of these microbial oils is higher than in initial substrate, which indicates that they can be interesting as a potential source to food supplements. Besides intracellular lipids accumulation, a simultaneous production of lipase (from WCO) and citric acid and lipase (from lard) was observed, demonstrating that a biorefinery approach may be designed based on fat raw materials, allowing at the same time the reduction of fatty wastes surplus. 